\title{
STATISTICAL OPTIMIZATION OF CHITIN BIOCONVERSION TO PRODUCE AN EFFECTIVE CHITOSAN IN SOLID STATE FERMENTATION BY Asperigellus flavus
}

\author{
Reem W. Yonis \\ Lecturer \\ Dep. of Biot. Coll. of Sci. University of Baghdad - Iraq \\ khalidluti@yahoo.com
}

Ghazi M. Aziz

Prof.

\section{ABSTRACT}

The aim of this study is to develop a bioconversion process of chitin to chitosan in solid-state fermentation. A classical optimization of one factor at the time was performed and revealed that maximum chitin deacetylase (CDA) production can be obtained in corn medium moisturized with mineral salt solution and with an initial moisture of $1: 1$ level (w/v). Results showed that $3 \%$ of spore inoculum contained $1 \times 10^{6}$ provided maximum production of CDA enzyme (219.5 U/g solid medium) after 5 days of incubation. Moreover, process parameters were systemically evaluated to improve the bioconversion of chitin to chitosan by statistical optimization using response surface methodology. The maximum production of chitosan of was reached to $27.3 \mathrm{mg} / \mathrm{g}$ media by using $1 \%$ chitin after 15 days of incubation with predicted chitosan concentration of $26.2 \mathrm{mg} / \mathrm{g}$. From ANOVA table. Time was the most significant factor in chitosan production with F-value 1014.5 and construction of empirical model building with determination coefficient $R^{2}=0.994$. The physiochemical characteristic of the produced chitosan in terms of degree of deacetylation, viscosity, chemical structure revealed high compatibility with the commercial chitosan. Result revealed that the chitosan produced in this study has a broad spectrum of antimicrobial activity against human pathogens: including Streptococcus spp., Staphylococcus aureus, Escherichia coli, Pseudomonas aeruginosa and Candida albicans.

Keyword: Bioconversion; SSF; RSM; Immobilization; CDA enzyme; Antimicrobial

*Part of Ph.D. Dissertation of the $1^{\text {st }}$ author

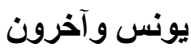

$$
\begin{aligned}
& \text { مجلة العلوم الزراعية العراقية -927-916:50) 2019) }
\end{aligned}
$$

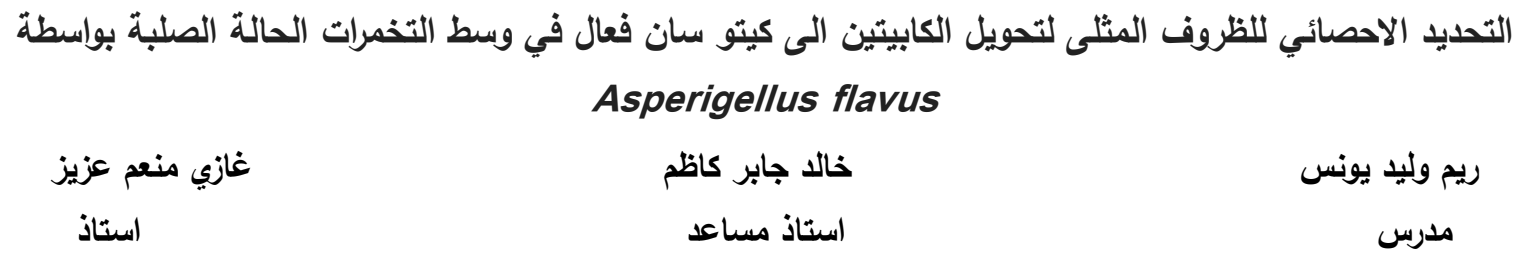

khalidluti@yahoo.com

\begin{abstract}
المستخلص
تهف الدراسة الى زيادة كفاءة عملية تحويل الكابيتين إلى الكيتوسان باستخام تخمرات الحالة الصلبة. تم اولا تحديد الظروف المثلى بالطريقه التقليديه

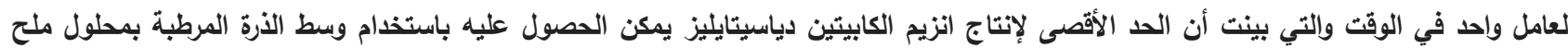

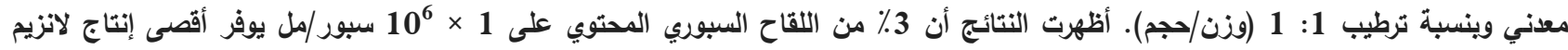
CDA

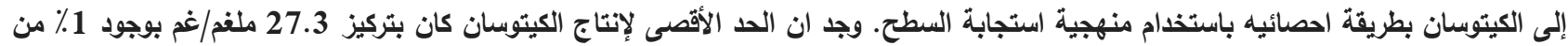

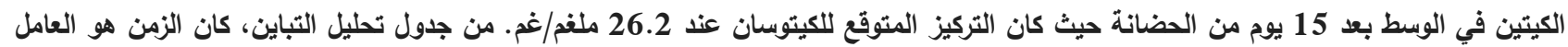
الأكثر أهمية في إنتاج الكيتوسان مع قيمة

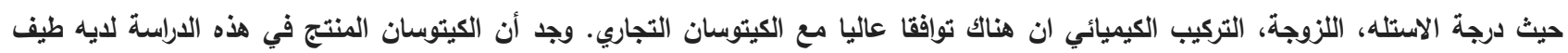
واسع من النشاط الضد ميكروبي ضد مسبيات الأمراض البشرية مثل: Streptococcus sp و Staphylococcus aureus و .Candida albicans و Pseudomonas aeruginosa goli

الكلمات المفتاحية: التحول الحياتي، تخمرات الخاله الصلبة، منهجية استجابة السطح، التقييد، انزيم كابيتين دياسيتايليز، مضادات مايكروبيه-

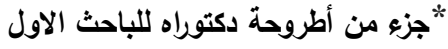




\section{INTRODUCTION}

Chitosan is a (1-4) -2- amino- deoxy- $\beta$-glucan biopolymer that broadly used in various applications such as pharmaceutical, biomedicine, food industry, water treatment, agriculture and in cosmetic. It considers as the most second abundant biopolymer after cellulose because of its bio renewability, bio degradability, biocompatibility and hydrophilicity (27). Usually, chitosan produces by an enzymatic method via chitin deacetylase (CDA) which is already obtained from different species of microorganism in particular fungi. The mycelia of various fungi such as Aspergillus niger (19), Mucor rouxii (23), Absidia coerulea, Rhizopus oryzae (24) are valuable sources of this enzyme and chitosan production. The statistical method of response surface methodology (RSM) was effectively applied in several studies to optimize fermentation variables in order to elevate the production of different microbial products. Mainly, this method involves construct an empirical model to investigate the interaction between the effected fermentation variables and the response and then statistically analyse the variance (15). On the other hand, the classical method of one factor at a time (OFAT) include alteration of one variable while keeping all other at a fixed level. This method is therefore, requires a large number of experiments to determine the optimum level which represent a real restriction. The statistical optimization is generally described as the best method to overcome the restrictions in the classical optimization in terms of laborious and timeconsuming. In the present study, a statistical optimization based on central composite design was applied to optimize the bioconversion of chitin to chitosan in solid state fermentation by Aspergillus flavus. In addition, a classical method was used to optimize the production of CDA enzyme by Aspergillus flavus in order to affect positively the bioconversion process.

\section{MATERIALS AND METHODS}

\section{Microorganism}

Aspergillus flavus stock culture was cultivated on potato dextrose agar (PDA) and incubated at $30 \mathrm{C}^{\mathrm{O}}$ for 7 days. Spores of A. flavus was prepared by adding $5 \mathrm{ml}$ of sterilized distilled water to the fungal culture vial on potato dextrose agar (PDA). The surface of agar culture was gently streaked using loop. Then spore suspension was transferred to sterilized container and counted by hemocytometer.

\section{Solid-state fermentation and classical optimization}

Ten grams of solid substrate was prepared in $100 \mathrm{ml}$ flask and $10 \mathrm{ml}$ of moisture solution was added to wet the solid content. The flasks were autoclaved at $\quad 121 \mathrm{C}^{\circ}$ for $20 \mathrm{~min}$ and then inoculated with $2 \%$ of spore suspension contained approximately $1 \times 10^{6}$ and incubated at $30 \mathrm{C}^{\mathrm{o}}$ for 7 days. Fermentation parameters were studied and optimized as follow: substrates of rice, corn, rice bran and wheat bran (separately and supplemented with $2 \%$ chitin) were tested for supporting growth of Aspergillus flavus and production of CDA enzyme. In addition, four different solutions were tested as a moisture solution involved distilled water, tap water, $1 \%$ chitosan and mineral salt solution contained per 1L: $2 \mathrm{~g} \mathrm{~K}_{2} \mathrm{HPO}_{4}$ and $1 \mathrm{~g} \mathrm{MgSO}_{4} \cdot 7 \mathrm{H}_{2} \mathrm{O}$. These solutions were tested at five level $(0.5: 1,1: 1,1.5: 1$, $2: 1, \quad 2.5: 1 \quad \mathrm{ml}: \mathrm{g}$ substrate). Furthermore, inoculation ratio with spore suspension that contains approximately $1 \times 10^{6}$ spores/ $\mathrm{ml}$ was also tested at five level $0.5,1,2,3,4 \%$.

\section{Statistical optimization of chitin bioconversion}

Response surface methodology based on central composite design was applied for maximizing chitin bioconversion. Basically, chitin concentration and fermentation time are the most possible factors that may affect the bioconversion of chitin to chitosan therefore, they were selected to generate the experimental matrix by $\mathrm{CCD}$ with chitin concentration level from 1 to $3 \%$ and incubation time from 5 to 15 days. The matrix was designed with 12 runs and four replications of centre point, four axial points and four factorial points. All runs (flasks) were prepared as described in the previous section under optimal conditions for CDA enzyme production. At the end of incubation, chitosan weight was measured.

\section{Preparation of chitin}

Chitin was prepared from three different sources, which then used as a substrate for the bioconversion process to produce chitosan. The procedures used to prepare chitin sources was based on the methods described by (31) 
for fungal chitin; (3) for chitin from mushroom and (26) for chitin from shrimp shell.

\section{Determination of CDA enzyme activity}

CDA enzyme was first extracted from the solid fermented substrate after 5 days of incubation by adding $40 \mathrm{ml}$ of distilled water and then the mixture was shaken for $2 \mathrm{hr}$. Thereafter, the mixture was filtrated by cotton gauze and then centrifuged at $10000 \mathrm{rpm}$ for $30 \mathrm{~min}$ at $4^{\circ} \mathrm{C}$. The enzyme activity in the supernatant was measure according to the method described by Sun and Coworkers (22) which based on measuring the amount of 4nitroaniline released from 4-nitroacetanilide at OD $400 \mathrm{~nm}$. One unit of CDA is defined as the enzyme activity that release $1 \mu \mathrm{g}$ of 4nitroanilin per hour from 4-nitroacetanilid under standard assay conditions.

\section{Chitosan determination}

At the end of incubation, solid mass was homogenized, and $1 \mathrm{M} \mathrm{NaOH}(1: 30 \mathrm{w} / \mathrm{v})$ was added to extract residual proteins and other alkali insoluble materials (AIMs). The mixture was then autoclaved at $121^{\circ} \mathrm{C}$ and 15 psi for 15 min. Thereafter, AIMs were recovered and then washed several times with distilled water to obtain neutral $\mathrm{pH}$. Next, the washed AIMs were dried at $60^{\circ} \mathrm{C}$ overnight and then weighed. Chitosan was extracted from AIM with $2 \%$ acetic acid $(1: 40 \mathrm{w} / \mathrm{v})$ in an autoclave for $15 \mathrm{~min}$ followed by centrifugation at $10000 \mathrm{rpm}$ for $15 \mathrm{~min}$. AIMs were discarded and $\mathrm{pH}$ of the supernatant was adjusted to 10 with $4 \mathrm{M}$ of $\mathrm{NaOH}$ which then left overnight at room temperature. Thereafter, the liquid was centrifuged to collect the precipitate and then washed with distilled water and weighed. The precipitated chitosan was washed with $95 \%$ ethanol $(1: 20 \mathrm{w} / \mathrm{v})$ and acetone $(1: 20 \mathrm{w} / \mathrm{v})$ and then dried at $60^{\circ} \mathrm{C}(18)$.

\section{Characterization of chitosan}

Fourier transform infrared spectroscopy FT-IR analysis was evaluated for the produced chitosan and compared with a commercial chitosan (company). The analysis was achieved using dried chitosan mixed with $\mathrm{KBr}$ powder which pressed into pellet for FTIR spectroscopy with frequency range of 4,000 $400 \mathrm{~cm}^{-1}$. Viscosity of chitosan was determined in $2 \%$ acetic acid solution using a viscometer (type/C-timing bulbs) at $25^{\circ} \mathrm{C}(19)$. Degree of deacetylation of chitosan was determined according to Yuan and coworker (32) as follow: $\quad 10 \mathrm{mg}$ of chitosan was dissolved in $10 \mathrm{ml}$ of $0.01 \mathrm{M} \mathrm{HCl}$-solution. After the chitosan dissolved completely, the solution was diluted to $100 \mathrm{ml}$ with de-ionized water. The concentration of Nacetylglucosamine was determined from the standard curve of different concentrations of $\mathrm{N}$ - acetylglucosamine at $199 \mathrm{~nm}$. The degree of deacetylation was determined according to equation:

Where:

$$
D D A=100 \%-C 1 / C
$$

$\mathrm{C} 1$ = Acetyl concentration of sample (OD 199nm)

$\mathrm{C}=$ Concentration of sample $(0.1 \mathrm{mg} / \mathrm{ml})$

\section{Chitosan as an antimicrobial agent}

Antimicrobial activity of chitosan was tested against human pathogenic microorganisms of Streptococcus, Staphylococcus aureus, Escherichia coli and Pseudomonas auroginosa. As well as against Candida spp.by well diffusion method as described by Johney et al., (14).

Chitosan as a support material for enzyme immobilization

Peroxidase enzyme was immobilized in a covalent linkage to chitosan based on the method described by Carrara and Ruubiolo, (7). one gram of the produced and commercial chitosan, separately, was added to $10 \mathrm{ml}$ of $2 \%$ gluteraldehyde solution and mixed for at least 2 hours at $4^{\circ} \mathrm{C}$ followed by incubation overnight at the same temperature. In order to remove the unbounded glutaraldehyde, the gluteraldehyde-bounded chitosan was washed 4 times with distilled water and then mixed with $10 \mathrm{ml}$ of crude enzyme solution which then left at least 24 hours at $4^{\circ} \mathrm{C}$. Next, chitosan - gluteraldehyde - peroxidase conjugate was separated from the solution and the free peroxidase activity was determined. The resulted conjugated chitosan was washed with $50 \mathrm{ml}$ of distilled water under vacuum pump. Immobilization with chitosan was tested by using peroxidase enzyme extracted from red radish by using sodium phosphate buffer ( $\mathrm{pH}$ 7) according to the method described by Silva and coworkers (20). The activity of peroxidase enzyme was determined based on the method of Whitaker and Bernhard (28). The ratio of enzyme 
immobilization for both produced and commercially chitosan was calculated according to the following equation: Immobilization ratio $(\%)=$ free enzyme activity/ number of immobilized enzyme unit.

Application of immobilized peroxidase in chitosan for dyes decolonization

The black, red, yellow and blue textile dyes obtained from Al-diwanyiah textile factory in Iraq, were used for testing the decolorization capability of immobilized peroxidase in chitosan, the method was described by AlAssadi et al, (1) with some modification as follow: the reaction mixture for the degradation of dyes contained $5 \mathrm{ml}(\mathrm{w} / \mathrm{v})$ of each dye and $1 \mathrm{ml}$ of free enzyme or $0.2 \mathrm{~g}$ of immobilized peroxidase in produced or commercial chitosan. The reaction mixture was incubated at $30^{\circ} \mathrm{C}$ for 24 hours. The blanks included $5 \mathrm{ml}$ of each textile dye, separately with $1 \mathrm{ml}$ of distilled water. After the end of incubation, centrifuge at 3000rpm for $10 \mathrm{~min}$ was performed and then the percentage of removal efficiency for each dyes was calculated via measuring the absorbance at $\max \lambda$ according to (33). Then the percentage of dyes degradation was estimated according to the following equation:

$$
\text { Dye declorization } \frac{A-B}{A} \times 100
$$

Where:
A: initial absorbance
B: final absorbance

\section{RESULTS AND DISCUSSION}

Chitin deacetylase enzyme (CDA enzyme) catalyses the bioconversion of chitin to chitosan via the deacetylation of $\mathrm{N}$ acetylglucosamine. Therefore, the amount of this enzyme produced in the medium can basically represent one of the most important parameters that control the bioconversion process. Thus, for the development of a controllable process for the bioconversion of chitin to chitosan, it was necessary to determine the optimal conditions that lead to maximize the production of CDA enzyme in the solid medium. Classical optimization of one factor at time method was performed in order to determine the solid substrate and moisture solution as well as the level of moisture and inoculum that support maxim production of CDA. As can be seen in fig. (1) corn supporting with $2 \%$ chitin showed the highest production of CDA with approximately $219.5 \mathrm{U} / \mathrm{g}$ substrate. moreover, initial moisture is a vital parameter in solid substrate fermentation that can significantly affect both the growth and enzyme production. Based on the results presented in figure 1, maximum production of CDA was obtained in culture moisturized with 1:1 level $(w / v)$ of mineral salt solution. Furthermore, five inoculation levels of the fungus spore suspension were examined ranging from 0.5 to $4 \%$ each contains a fixed concentration of spores. According to the results presented in fig. (1), $3 \%$ of spore inoculum provide maximum production of CDA enzyme under the experimental conditions used in this work. Therefore, in order to achieve the bioconversion process in the solid substrate fermentation, and to ensure that maximum amount of chitin can be converted to chitosan, the bioconversion was performed under conditions described in Fig.1. The next step in this work was to find the optimal conditions for chitosan production statistically by RSM via evaluating two fermentation parameters; time and chitin concentration; that basically represent the factors that govern the bioconversion process, Table 1 shows the level and range of each parameter. Twelve experiments were conducted by central composite design matrix as elucidated in Table 2 which also show the actual and predicted response for each run.

Table 1. Variables and their levels in the experimental design

\begin{tabular}{|c|c|c|c|c|c|}
\hline factor & $-\alpha$ & -1 & 0 & 1 & $+\alpha$ \\
\hline Time (day) & 2.92 & 5 & 10 & 15 & 17.07 \\
Chitin (\%) & $\mathbf{0 . 5 8}$ & 1 & 2 & 3 & 3.4 \\
\hline
\end{tabular}




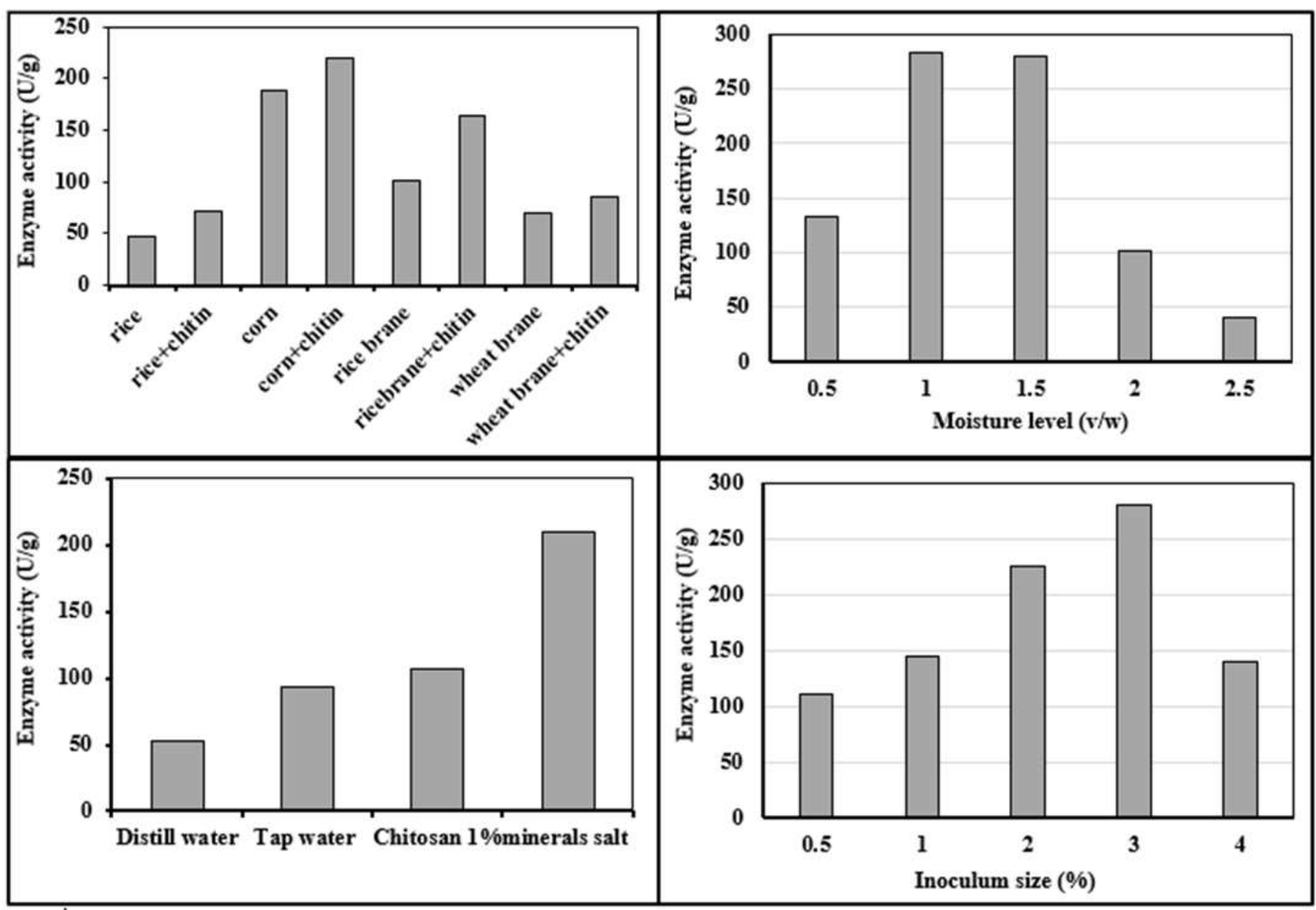

Figure 1. Optimum conditions for CDA enzyme production by Aspergillus flavus in solid-state fermentation

Table 2. Central composite design matrix in uncoded units along with actual and predicted response for chitosan production

\begin{tabular}{|c|c|c|c|c|c|c|}
\hline \multicolumn{2}{|c|}{} & \multicolumn{2}{c|}{ Factors } & \multicolumn{2}{c|}{ Chitosan (mg/g) } \\
\hline Std & Run & point type & Time (day) & Chitin (\%) & Actual & Predict \\
\hline 2 & 1 & Fact & 15 & 1 & 27.3 & 26.2 \\
4 & 2 & Fact & 15 & 3 & 23.38 & 22.7 \\
9 & 3 & Center & 10 & 2 & 16.8 & 16.8 \\
1 & 4 & Fact & 5 & 1 & 5.25 & 5.1 \\
6 & 5 & Axial & 17.07 & 2 & 26.6 & 27.62 \\
11 & 6 & Center & 10 & 2 & 16.1 & 16.8 \\
5 & 7 & Axial & 2.92 & 2 & 0.7 & 0.52 \\
12 & 8 & Center & 10 & 2 & 17.5 & 16.8 \\
10 & 9 & Center & 10 & 2 & 16.8 & 16.8 \\
3 & 10 & Fact & 5 & 3 & 5.39 & 5.65 \\
7 & 11 & Axial & 10 & 0.585786 & 15.96 & 16.7 \\
8 & 12 & Axial & 10 & 3.414214 & 14.7 & 14.77 \\
\hline
\end{tabular}

Based on response values and data analysis as using determination coefficient $\left(\mathrm{R}^{2}\right)$ which well as from the fit summary analysis, quadratic model was the most suggested model for chitosan production according to lake of fit test and P-value (0.169). Analysis of variance, ANOVA, for quadratic improved model was performed to check adequacy and significance of model Table 3. Model fitness was evaluated was 0.994 indicating that 0.006 of total the variation was not explained by the model. Adequate precision for chitosan was 45.05; this value was used for measuring signal to noise which believed to be desirable greater than 4. The adjusted and predicted determination coefficients for chitosan were 
0.989 and 0.962 respectively which are accepted values as the difference between them is less than 0.2. From the table of ANOVA for chitosan production, it can be seen that all terms show significant effect except for B2 (chitin \%) which is not significant. Since most of the $\mathrm{P}$ value data show 0.0001 , therefore the highest significant factors can be determined through F- value. Atime shows the most significant factor affecting on chitosan production with F- value
1014.53 followed by $\mathrm{A}^{2}$ with F- value 16.4. In addition, a regression equation which is imperical relationship between tested variables and response was generated. after analysis of variance and estimation of regression coefficient, the experimental design was fitted in second order polynomeal equation and in coded factors where A: time, B: chitin concentration

Chitosan $=16.8+9.58 * \mathrm{~A}-0.695 * \mathrm{~B}-$ $1.015 * \mathrm{~A} * \mathrm{~B}-1.36 * \mathrm{~A}^{2}-0.525 * \mathrm{~B}^{2} \ldots 1$

Table 3. ANOVA analysis of quadratic model for chitosan production base on CCD

\begin{tabular}{|c|c|c|c|c|c|c|}
\hline Source & $\begin{array}{c}\text { Sum of } \\
\text { Squares }\end{array}$ & df & $\begin{array}{l}\text { Mean } \\
\text { Square }\end{array}$ & $\begin{array}{c}\text { F } \\
\text { Value }\end{array}$ & $\begin{array}{c}\text { p-value } \\
\text { Prob }>\text { F }\end{array}$ & \multirow[b]{2}{*}{ significant } \\
\hline Model & 755.086 & 5 & 151.0172 & 208.5224 & $<0.0001$ & \\
\hline A-Time & 734.7503 & 1 & 734.7503 & 1014.533 & $<0.0001$ & \\
\hline B-chitin & 3.866854 & 1 & 3.866854 & 5.339297 & 0.0602 & \\
\hline AB & 4.1209 & 1 & 4.1209 & 5.69008 & 0.0544 & \\
\hline$A^{\wedge} 2$ & 11.92464 & 1 & 11.92464 & 16.46537 & 0.0067 & \\
\hline $\mathrm{B}^{\wedge} 2$ & 1.764 & 1 & 1.764 & 2.435706 & 0.1696 & \\
\hline Residual & 4.345352 & 6 & 0.724225 & & & \\
\hline Lack of Fit & 3.365352 & 3 & 1.121784 & 3.434033 & 0.1690 & not significant \\
\hline Pure Error & 0.98 & 3 & 0.326667 & & & \\
\hline Cor Total & 759.4314 & 11 & & & & \\
\hline
\end{tabular}

R-sq= 0.994 adj R-sq =0.989 pred R-sq=0.966 adeq precession $=45.05 *$ not significant

In addition to correlation, regression analyses can be used to assess the best fit of a line using the equation $y=b_{0}+b x_{i}$. The ideal line of best fit will have the sum of the squares of the distances from $x$ to the line of fit as small as possible. The diagnostic of normal residual demonstrated in Fig. 2 indicate that residual behavior followed normal distribution and was quadratic, which is the more important assumption for checking statistical modeling. Moreover, the predicted output values versus actual experimental values for chitosan production are presented in Fig. 3. From this figure, it can be noted that the experimental values were in a significant agreement with values calculated by the predictive quadratic model with a satisfactory correlation. Therefore, it can be said that the developed model is suitable for predicting chitosan concentration under suggested conditions.

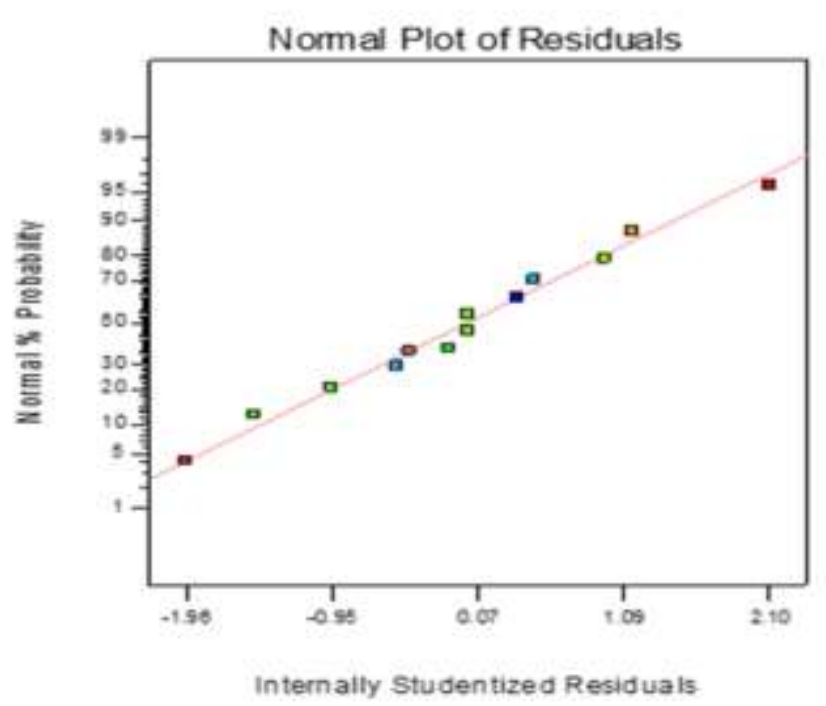

Figure 2. Normal probability plot of standardized residuals of quadratic model based on CCD for chitosan production 


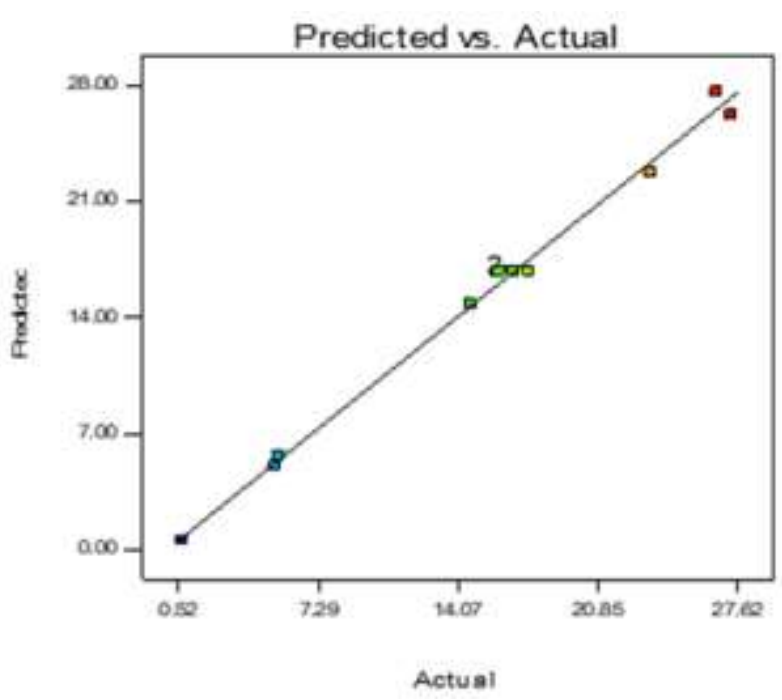

Figure 3. Actual versus predicted values for chitosan production

Contour curves surface help to visualize and understand the kind of interaction between parameters and the response in order to conclude the optimum conditions. These plots can be obtained from the model; the values taken by one factor while the second was varies from $-\alpha$ to $+\alpha$ with constrain of given response. Fig. 4 shows the interaction between time and chitin concentration, with various values from lowest to highest level. Contour plot revealed that maximum chitosan production of $27.3 \mathrm{mg} / \mathrm{g}$ which is illustrated as a red region of plot can be obtained with $1 \%$ of chitin in 15 days

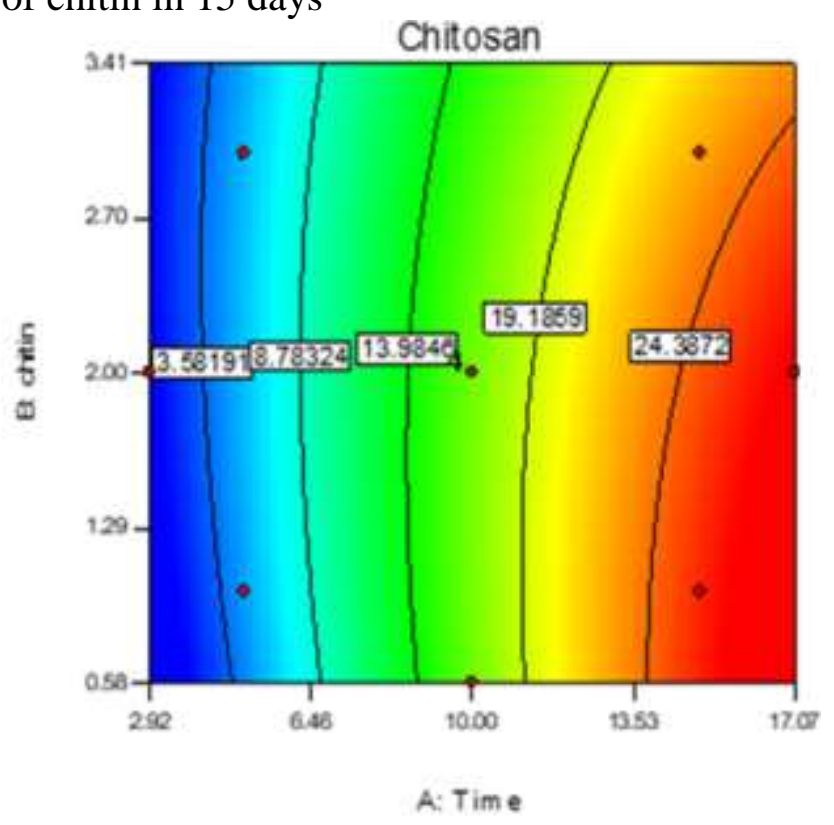

Figure 4. Effect of interaction factors for time and chitin concentration for chitosan production

Based on the enhanced regression model, optimization plot can be generated using the
Design expert 7 software in order to determine the best time and chitin concentration that give maximum concentration of chitosan. results showed that maximum predicted concentration of chitosan can be produced with the optimum incubation time (15 day) and chitin concentration $(1 \%)$ is $26.2 \mathrm{mg} / \mathrm{g}$. In order to verify the suggested optimum conditions and determine the accuracy of model, an experiment was conducted in duplicate using chitin from three different sources (Fungus, shrimp shell, mushroom) all were prepared in the laboratory as described earlier in materials and methods. As can be seen in Fig. 5, the amounts of chitosan produced by the bioconversion process were approximately similar ranging from 24.1 to $25.2 \mathrm{mg} / \mathrm{g}$ which approximately closed to the predicted value. However, the degrees of deacetylation were different. In addition, Fig. 5 shows the maximum degree of deacetylation was observed in chitosan obtained from fungal chitin $(78.4 \%)$ whereas the minimum DDA was in the chitosan produced from the shrimp shell $(74.8 \%)$. In general, the most common sources of chitin were crab shells and from shrimps which are wastes of marine products (2). During the last years, chitin extracted from fungal mycelia has gained more interesting (3). In reviewing the literature, a strong relationship between degree of chitin crystallinity and CDA activity has been reported. In this context, Cai et al., (6) reported that water-soluble chitosan and chitin produced from $A$. niger were amorphous, whereas the crystallinity of chitin from shrimp was high that made the interaction between its molecules robust. Therefore, in such a case, it is difficult for the CDA enzyme to access the acetyl groups. Thus, in order to increase the deacetylation rate for shrimp chitin, a pretreatment of destroying the crystalline structure is required prior to bioconversion process. In addition, Cai et al., (6) found that enzyme produced from Scopulariopsis brevicaulis had high deacetylating activity on chitin obtained from A. niger mycelium (37\% deacetylation), whereas the activity on shrimp crystalline chitin was $3.7 \%$. On the other hand, the degree of deacetylation for the produced chitosan was investigated during the bioconversion process. As can be seen from 
the Fig. 6, the amounts of chitosan produced after 3 days of incubation was few $(2.1 \mathrm{mg} / \mathrm{g})$ and then increased during the fermentation reaching to the optimum after 15 days of incubation. However, degree of deacetylation was a little high after 3 days of incubation $(83.35 \%)$ and then decreased slightly to $(81 \%)$ after 15 days of incubation. Bioconversion of chitin to chitosan were investigated for several years since the first observation of CDA enzyme, though, a high degree of deacetylation is still difficult to attain, principally because of the insoluble and crystalline nature of chitin (4). Therefore, in order to obtain an efficient biotransformation, several techniques were used to improve chitin properties via reducing its crystallinity and hence, effect the amorphous structure of chitin which is necessary for CDA to access and produce chitosan (5). Examples of these techniques involved grinding, interaction with saccharides, sonicating, and heating (29). The degree of deacetylation is an important parameter as it is affecting the physicochemical properties of chitosan. Chitosan with high degree of deacetylation has high positive charges that make it more appropriate for different application in food and medicine (10). It is widely mentioned that, chitosan produced by the thermochemical deacetylation process is non-specific with great inconsistency in the degree of deacetylation (30).

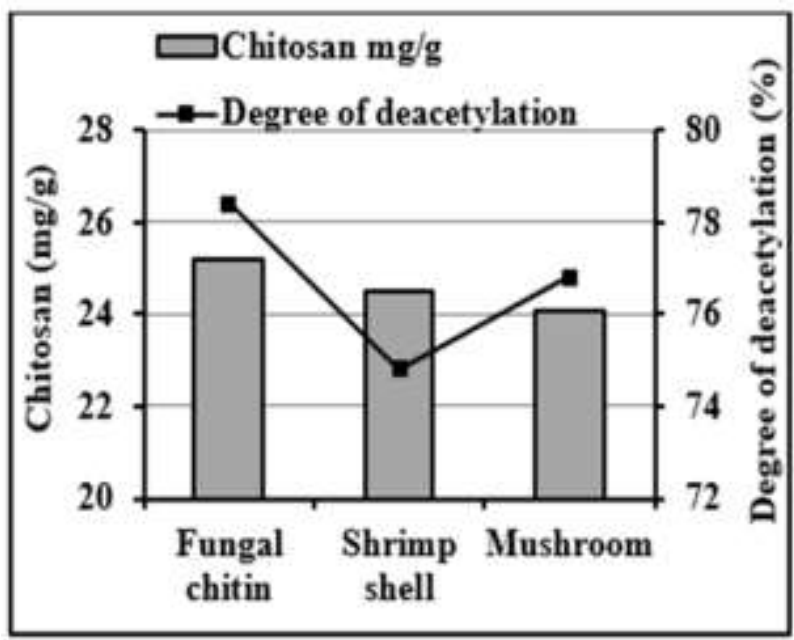

Figure 5. Production and degree of deacetylation of chitosan produced by Aspergillus flavus using chitosan obtained from mold, shrimp shell and mushroom in solid-state fermentation.

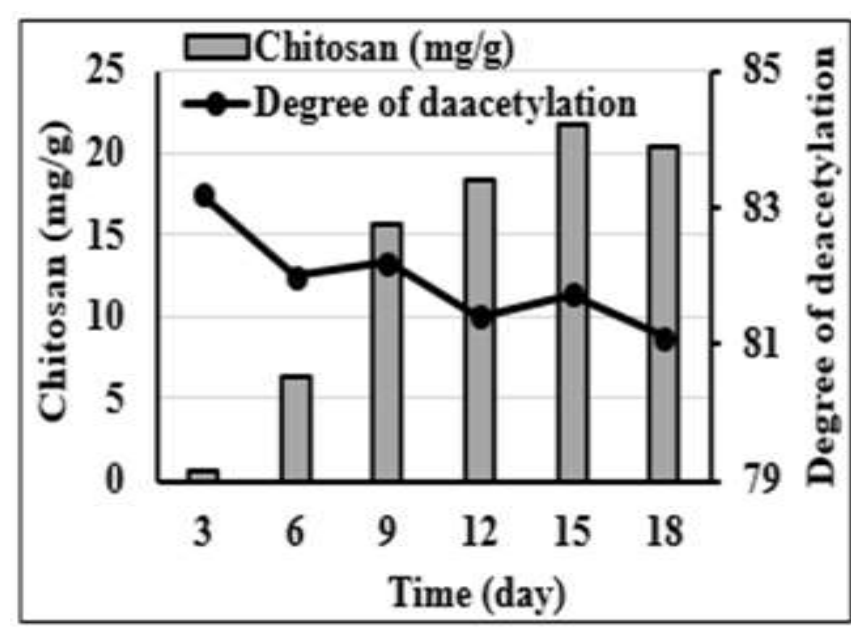

Figure 6. Degree of deacetylation of chitosan produced in different time during the bioconversion of fungal chitin in solidstate fermentation by $A$. flavus

FT-IR spectrum (4000 to 400 ) $\mathrm{cm}^{-1}$ was used to identify and confirmed the characteristic functional groups of the produced chitosan. The isolated fractions gave IR spectra similar to that of the commercial chitosan from crab shells. As can be seen from the FT-IR spectra presented in Fig. 7, a broad absorption band in the range of $3000 \mathrm{~cm}^{-}{ }^{1}-3500 \mathrm{~cm}^{-}{ }^{1}$ is found which is attributed to $\mathrm{O}-\mathrm{H}$ stretching vibrations and at $1400-1650 \mathrm{~cm}-1$ refer to $\mathrm{C}=\mathrm{O}$ bond (9). In addition, the peaks around $2885,1650,1589,1326$ and $1080 \mathrm{~cm} \mathrm{-}^{-1}$ are assigned to the stretching vibrations of aliphatic $\mathrm{C}-\mathrm{H}$, Amide I (-NH deformation of $-\mathrm{NHCOCH} 3$ ), Amide II, Amide III and $\mathrm{C}-\mathrm{O}-$ $\mathrm{C}$, bonds respectively (11). According to IR spectra results, the basic molecular structure of both produced and commercial chitosan is significantly similar. On the other hand, the dynamic viscosity of the produced chitosan was 5.6 centipoises $(\mathrm{cP})$, which is considerably lower than the viscosity of the commercial chitosan 25.77 (cP). In this context, Khalaf (16) reported that chitosan produced by fungal strain Rhizopus oryzae in rice straw in SSF for 12 days was 6.8 centipoises (cP).

Chitosan as an antimicrobial agent

In recent years, there has been an increasing amount of literature that investigated the spectrum activity of chitosan against different group of human pathogenic microorganisms (14). It is believed that the mechanism of antimicrobial chitosan activity is based mainly on its interaction with anionic groups on the cell surface, due to its polycationic nature, that 
causes the formation of an impermeable layer around the cell, which consequently prevents the transport of essential solutes (12). The antimicrobial activity of chitosan produced in this work was evaluated against some human pathogenic microorganisms. As can be seen in Table 4 and Fig. 8, a significant activity was observed for chitosan produced in this study against all tested microorganisms at a level similar to that observed with commercial chitosan. Interestingly, the results, as shown in Table 4, indicate that the inhibitory activity of chitosan was rather more than the antimicrobial activity of Amikacin disc, which certainly has important implications for future work.

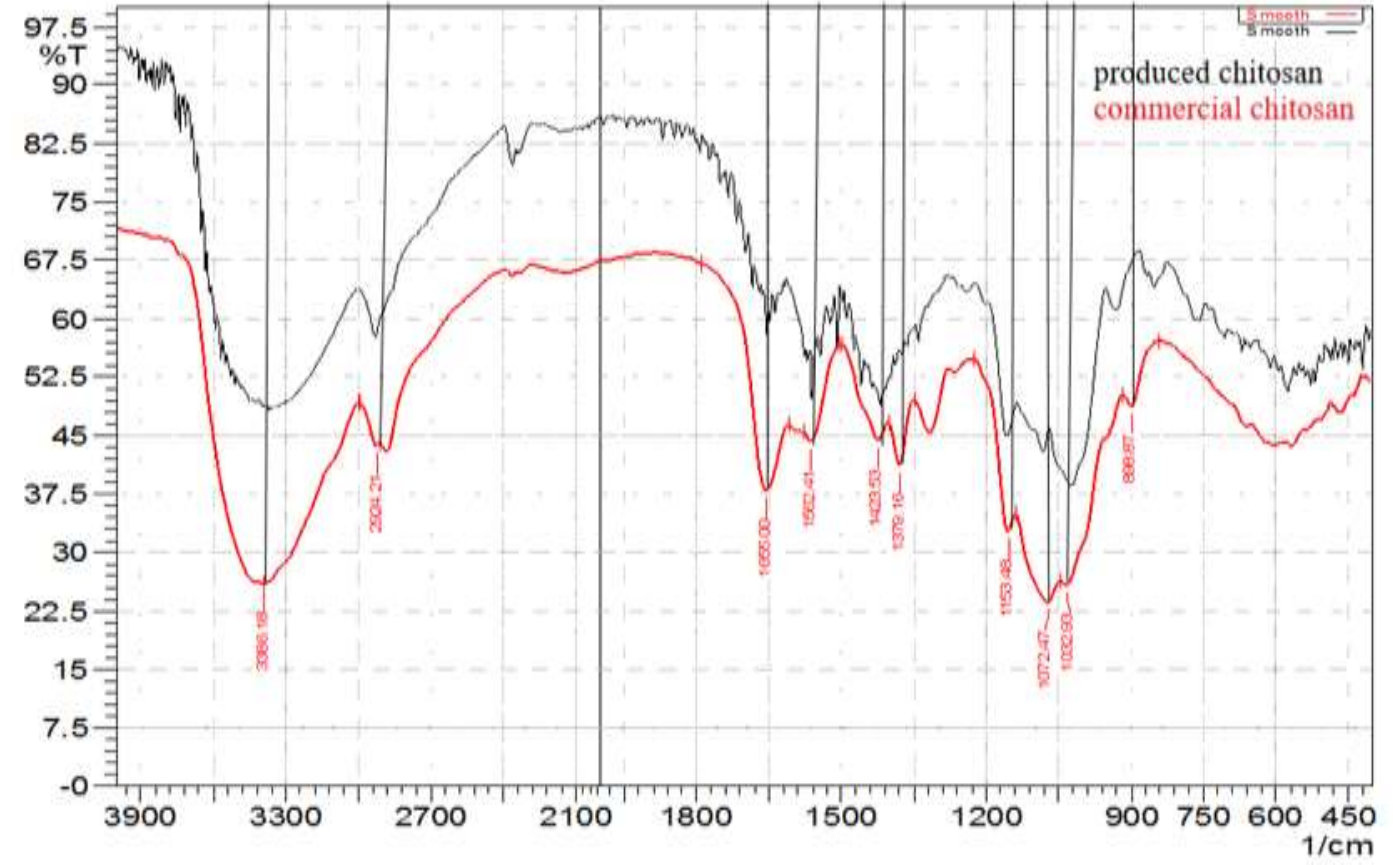

Figure 7. FT-IR spectra of commercial and produced chitosan from A. flavus

Table 4. Antimicrobial activity of chitosan against some pathogenic microorganisms

\begin{tabular}{|l|c|c|c|}
\hline \multirow{2}{*}{\multicolumn{1}{|c|}{ Strain }} & \multicolumn{3}{|c|}{ Diameter of inhibition zone (mm) } \\
\cline { 2 - 4 } & $\begin{array}{c}\text { Commercial } \\
\text { chitosan }\end{array}$ & $\begin{array}{c}\text { Produced } \\
\text { chitosan }\end{array}$ & $\begin{array}{c}\text { Amikacin disc } \\
(30 \mu \mathrm{g})\end{array}$ \\
\hline Escherichia coli & 25 & 24 & 19 \\
Pseudomonas aeruginosa & 26 & 25 & 18 \\
Streptococcus spp. & 25 & 25 & 19 \\
Staphylococcus aureus & 28 & 28 & 14 \\
Candida spp. & 19 & 20 & 17 \\
\hline
\end{tabular}

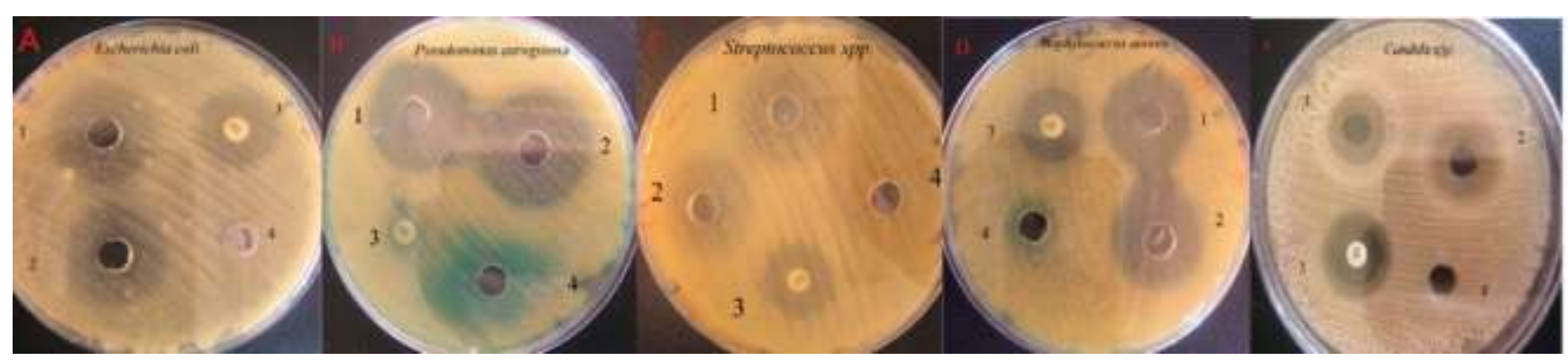

Figure 8. Antimicrobial activity of commercial chitosan (1), produced chitosan (2), Amikacin disc (30 $\mu \mathrm{g})(3)$ and $0.1 \%$ acetic acid as a control (4) against different pathogenic microorganisms

Chitosan as a support material in resulting insoluble polymers, however the peroxidase immobilization

Peroxidase enzyme catalyze the oxidative polymerization of phenolic compounds lifetime of this enzyme is generally short (13). In order to overcome this drawback, the enzyme is used in the immobilized form and 
therefore, it can be used with a long lifetime (34). The immobilizing process of an enzyme to an activated support is leading to reduce or loss the mobility of the enzyme. This technique causes a rigidification in the enzyme structure which decreased any possible conformational changes in the enzyme that cause inactivation and therefore, rising the stability of enzyme (17). One of the supported materials that successfully used for the immobilization of enzymes is chitosan. Crude peroxidase extract from red radish was immobilized by covalent linkage in chitosan produced in this study. As can be seen in Table 5 , immobilization was performed by adding free peroxidase enzyme with an activity of $561.44 \mathrm{U} / \mathrm{ml}$. Results showed that immobilization ratio of the enzyme to the produced chitosan was $63.10 \%$ in comparison with commercial chitosan which was $75.50 \%$. In this context, Chagas et al, (8) reported, based on their results, that chitosan was efficient for covalent immobilization of soya bean hull peroxidase. In addition, Skoronski et al, (21) immobilized laccase enzyme isolated from Asperigellus $s p$. in gluteraldehydeactivated chitosan with an immobilization ratio of up to $90 \%$ at $40^{\circ} \mathrm{C}$.

Application of immobilized peroxidase in chitosan for dye decolorization

Nowadays, phenols and their derivatives are discarded into the environment from different sources. These compounds are widely used in the manifacturing process of pertrolum refieries, papers, pestisides, dyes, drugs, plastics and textiles. Thus, the handling of indesterial wastes containing aronatic compouned is required prioer to their final release into the environment. One of the technique that successfully used in the degradation of phenolic compouneds is the utilization of peroxidases enzyme.
Table 5. Peroxidase immobilization using chitosan produced from Asperigellus flavus in comparison with commercial chitosan

\begin{tabular}{|c|c|c|c|}
\hline & $\begin{array}{c}\text { Free } \\
\text { peroxidas } \\
\text { e enzyme }\end{array}$ & $\begin{array}{c}\text { Produce } \\
\text { d } \\
\text { chitosan }\end{array}$ & $\begin{array}{l}\text { Commercia } \\
\text { l chitosan }\end{array}$ \\
\hline $\begin{array}{c}\text { Free enzyme } \\
(\mathrm{U} / \mathrm{ml})\end{array}$ & 561.44 & 207.15 & 137.45 \\
\hline $\begin{array}{c}\text { Immobilized } \\
\text { enzyme(U/mg } \\
\text { ) }\end{array}$ & & 100.67 & 125.12 \\
\hline $\begin{array}{c}\text { Number of } \\
\text { immobilized } \\
\text { units }\end{array}$ & & 354.29 & 423.99 \\
\hline $\begin{array}{c}\text { Immobilized } \\
\text { ratio }(\%)\end{array}$ & & 63.10 & 75.51 \\
\hline
\end{tabular}

In this study, the degradation capability of immobilized peroxidase with produced and commercial chitosan was studied using yellow, red, blue and black textile dyes at a concentration of $30 \mathrm{mg} / \mathrm{liter}$ for $24 \mathrm{hrs}$. The absorbance of each dye was recorded at a suitable wave length for each one. As can be seen in Table 6 , textile black exhibited higher degradation capacity with peroxidase that immobilized in commercial chitosan with maximum removal extent of $41 \%$ after $24 \mathrm{hrs}$, followed by textile red (31\%), then textile blue $(24.3 \%)$ and finally textile yellow (21\%). Whereas, immobilized peroxidase in produced chitosan gave the highest result of removal dye in black, red, blue and yellow textile with removal extent of 34, 27, 22.2 and $19.4 \%$ respectively. Moreover, free peroxidase has approximately the same effect to degrade dyes compared with the immobilized form. Furthermore, results in Table 6 revealed that these dyes were not decolorized at the same extent because each dye has different structure and redox potentials. This certainly affect the suitability of their steric structure with the active site of the enzyme and consequently the degradation capability of free peroxidase and that immobilized (25). 
Table 6. Dyes decolorization of free and immobilized peroxidase with produced and commercially chitosan after $24 \mathrm{hr}$ at time of incubation

\begin{tabular}{|l|c|c|c|}
\hline \multirow{2}{*}{ Dyes } & \multicolumn{3}{|c|}{ Dye degradation (\%) } \\
\cline { 2 - 4 } & Free peroxidase & \multicolumn{2}{c|}{ Immobilized enzyme } \\
\cline { 3 - 4 } & & commercial chitosan & produced chitosan \\
\cline { 4 - 4 } Textile black & 32 & 41 & 34 \\
\cline { 1 - 1 } Textile yellow & 17.3 & 21 & 19.4 \\
\cline { 1 - 1 } Textile red & 25.2 & 31 & 27 \\
\cline { 1 - 1 } Textile blue & 20 & 24.3 & 22.2 \\
\hline
\end{tabular}

\section{REFFERENCES}

1. Al-Assadi, M. Aziz, and H. Hydar. 2017. Biodegradation of industrial dyes in a bioreactor by free and immobilized laccase from local isolate of Pseudomonas aeruginosa SR3:164-167

2. Abdou ES, K. Nagy, and M. Elsabee, 2008. Extraction and characterization of chitin and chitosan from local sources. Bioresource Technology. 99(5):1359-1367

3. Álvarez O, R. Escobar, O. Rojas, DF .Vahos , P. Ocampo and L, Atehortúa .2014.Comparison of extraction methods of chitin from Ganoderma lucidum mushroom obtained in submerged culture. BioMed Research International.181:6738-6730

4. Araki Y. and E .Ito .1975. A pathway of chitosan formation in Mucor roxii and enzymatic deacetylation of chitin. Eur $\mathbf{J}$ Biochem. 55:71-78.

5. Beaney P.D, Q. Gan, T.R.A. Magee, M. Healy, and J. Lizardi-Mendoza. 2007. Modification of chitin properties for enzymatic deacetylation. J Chem Technol Biotechnol. 82:165-173.

6. Cai J, J.H .Yang, Y.M .Du, L.H .Fan, Y.L.Qiu, J.Li, and J.F. Kennedy. 2006. Purification and characterization of chitin deacetylase from Scopulariopsis brevicaulis. Carbohydrate Polymer 65:211-217.

$\begin{array}{llr}\text { 7. Carrara, C.R and A.C. } \\ \text { Rubiolo.1994.Immobilization } & \text { of } & \alpha-\end{array}$ galactosidase on chitosan. J Biotechnol 10:220-224

8. Chagas H, A. Torres, C. Silva and D. Correa.2015. Immobilization soybean hull peroxidase for the oxidation of phenolic compounds in coffee processing wastewater. Int. J biological macromolecules. 81:568-575.

9. Chatterjee S, M .Adhya, A.K. Guha and B.P. Chatterjee. 2005.Chitosan from Mucor rouxii: production and physico-chemical characterization. Proc Bioch .40:395-400.

10. Crestini, C., B .Kovac. and G. Giovannozzi-Sermanni. 2002. Production and isolation of chitosan by submerged and solidstate fermentation from Lentinus edodes. Biotechnol Bioeng. 50:207-210.

11. George TS, K.S. Guru, N.S.Vasanthi and K.P. Kannan.2011.Extraction purification and characterizationof chitosan from endophytic fungi isolated from medicinal plants. World $\mathbf{J}$ Sci Technol. 4: 43-48

12. Helander I, E. Nurmiaho-Lassila, R .Ahvenainen, Rhoades and J.Roller. 2001. Chitosan disrupts the barrier properties of the outer membrane of gram-negative bacteria. Int. J. Food Microbiol 71:235-44.

13. Huang O, R.A. Pinto, K .Griebenow, R. Schweitzed-Stenner and W.J. Weber.2005. Inactivation of hourseradish peroxidase by phenoxyl radical attack. J Am Chem Soc 127:1431-1437.

14. Johney J, K. Eagappan and R. Ragunathan.2017. Microbial extra action of chitin and chitosan from Pleurotus spp, its characterization and antimicrobial activity. Int J Cur Pharma Res. 7: 0975-7066.

15. Karthik N, P. Binod and A .Pandey. 2017. SSF production, purification and characterization of chitin deacetylase from Aspergillus flavus. Biocatalysis and biotransformation. 36:2018-4.

16. Khalaf S. 2004. Production and characterization of fungal chitosan under solid-state fermentation conditions. International Journal of agriculture and biology.8: 8530-1560

17. Khan M, and A. Azohairy. 2010. Hydrogen donor specificity of Mango isoperoxidase. J. Biol, Sci. 8: 565-575.

18. Mondala A, R. Al-Mubarak, J .Atkinson, S. Shields, B .Young, Y .Dos and J .Pekarovic. 
2010. Direct solid-state fermentation of soybean processing residues for the production of fungal chitosan by Mucor rouxii. J Material Sci Chem Eng. 3:11-21

19. Pochanavanich $P$ and $W$.Suntornsuk. 2002. Fungal chitosan production and its characterization. Let App Microbiol 35:17-21

20. Silva MC, A.D .Correa, M .Amorim, P .Parpot, J.A .Torres and P.M .Jagas,. 2012. Decolorization of the phthalocyanine dye reactive blue 21 by turnip peroxidase and assessment of its oxidation products. Mol. Catal B Enzyme. 77:9 -14.

21. Skoronski E, M .Fernandes, M. Magalhães, G. F. da Silva, J.J .João, Soares C.H.L. and A.F. Júnior. 2014. Substrate specificity and enzyme recycling using chitosan immobilized laccase. J of Molecules. 19: 16794-16809.

22. Sun Y, J .Zhang, S .Wu and S .Wang. 2014. Statistical optimization for production of chitin deacetylase from Rhodococcus erythropolis HG05. Carbohydrate Polymers 102:249-252.

23. Synowiecki J and N.A. Alkhateeb.1997. Mycelia of Mucor rouxii as a source of chitin and chitosan. Food chemistry. 60:605-610.

24. Tan SC, T.K .Tan, S.M .Wong and E .Khor. 1996. The chitosan yield of Zygomycetes at their optimum harvesting time. Carbohydrate Polymers 30:239-242

25. Tavares AP, R.O. Cristóvão, J.M. Loureiro, R.A.R. Boaventura and E.A. Macedo,. 2008. Optimization of reactive textile dyes degradation by laccase-mediator system. J Chem Tech Biotechnol. 83(12): 1609-1615.
26. Teli MD and J. Sheikh. 2012. Extraction of chitosan from shrimp shells waste and application in antibacterial finishing of bamboo rayon. International Journal of Biological Macromolecules .50:1195-1200.

27. Trzcinska M and W. Pachlewski. 1986. Chitin content of vegetative mycelia of some mycorrhizal fungi. Acta Microbiol .22:89-93.

28. Whitaker JR and R.A. Bernard .1972.

Experiments for an introduction of enzymology. The Wibber Press. Davis

29. Win N and W. Stevens. 2001. Shrimp chitin as substrate for fungal chitin deacetylase. Appl Microbial Biotechnol. 57:334-341.

30. Wu A and W .Bough. 1978. Proceedings of International Conference of Chitin/Chitosan.88-102.

31. Yen MT and J .Mau. 2007. Selected physical properties of chitin prepared from shiitakestipes. LWT-Food Sci Technol. 40(3):558-563.

32. Yuan Y, M .Betsy. C .Warren, O .Haggard and J. Bumgardner. 2011. Deacetylation of Chitosan: Material Characterization and in vitro Evaluation via Albumin Adsorption and Pre-Osteoblastic Cell Cultures. Journal of Materials. 4: 1399-1416.

33. Zhang Z, Y. Shan and J. Wang. 2007. Investigation on the rapid degradation of Congo red catalyzed by activated carbon powder under microwave irradiation. Journal of Hazardous Material. 147(1-2):325-333.

34. Zille $\mathrm{A}, \mathrm{T}$.Tzanov, $\mathrm{G}$.Gubitz and $\mathrm{A}$ .Cavaco-Paulo. 2003. Immobilization laccase for decolorization of reactive black 5 dyeing effluent. Biotechnol. Lett. 25:1473-1477. 